\title{
Polyethylene passive samplers to determine sediment-pore water distribution coefficients of persistent organic pollutants in five heavily contaminated dredged sediments
}

\author{
Charrasse Benoit ${ }^{1}$, Tixier Celine ${ }^{2}$, Hennebert Pierre ${ }^{1}$, Doumenq Pierre ${ }^{3,}{ }^{*}$
}

1 ARDEVIE, Inst Natl EnviRonnem Ind \& RiSques INERIS, F-13545 Aix En Provence 04, France.
2 IFREMER, RBE BE LBCO, F-44311 Nantes 3, France.
3 Aix Marseille Univ, CNRS, UMR CNRS 6263, Lab Chim Environnem,FRE 3416, F-13545 Aix En
Provence 4, France.

* Corresponding author : Pierre Doumenq, email address : Pierre.doumenq@univ-amu.fr

\begin{abstract}
:
Pore concentration and partition coefficients of polycyclic aromatic hydrocarbons (PAHs) and polychlorinated biphenyls (PCBs) were determined in sediments from five distinct contaminated sites in France (marine harbour, rivers canals and highway sedimentation tank). The assessment of the risk caused by such micropollutants requires, in most cases, the measurement of their availability. To assess this availability, low density polyethylene (LDPE) membrane samplers were exposed to these sediments under constant and low-level agitation over a period of 46 days. Freely dissolved pore water contaminant concentrations were estimated from the concentration at equilibrium in the LDPE membrane. The depletion of contaminants in the sediments was monitored by the use of performance reference compounds (PRCs). Marked differences in freely dissolved PAH and PCB concentrations and resulting sediment-pore water partition coefficients between these five sediments were observed. Data set was tested onto different empirical and mechanistic models. As final findings, triple domain sorption (a total organic carbon, black carbon and oil phase model) could model PCB data successfully whereas the best fitting for PAH partitioning was obtained by Raoult's Law model.
\end{abstract}

\section{Highlights}

- Hydrophobic organic compounds were determined in pore water in dredged sediments. Freely dissolved pore water concentrations were estimated by passive sampler. Sediment depletion was evaluated with performance reference compounds. Distribution coefficients were well predicted with empirical and mechanistic models.

Keywords : Passive sampling, Pore water concentration, PAHs, PCBs, Dredged sediments, Model comparison 


\section{Introduction}

In harbours and natural or man-made waterways, dredging is required to maintain a sufficient depth for navigation and to prevent risks of flooding. Among the 65 million tons dredged per year in France, and according to French regulations (Decree of August, the $9^{\text {th }}, 2006$ ), 6 million tons are considered contaminated, as they exceed the S1 threshold (for fluvial sediment) and the N2 threshold (for marine sediment)(INERIS, 2009). In addition to the fact that they cannot be submerged, as they are considered waste, their contamination hampers their valorisation. The management of such dredged materials takes into account the technical feasibility, economics, applicable regulations and environmental acceptability of different options (re-use, disposal, processing) and receives considerable attention at an international level. Dredged materials are often disposed off on sites, acting as a source for hydrophobic organic contaminants (HOCs). However, in the sedimentary material, strong sorption to pyrogenic organic carbon, also known as black carbon (BC), tends to reduce the potential of the emission and the (bio)availability of HOCs (Cornelissen et al., 2005; Koelmans et al., 2006). Indeed, sorption to BC, such as diesel soot, coal soot, wood charcoal, or char-like carbonaceous particles, renders obsolete the traditional equilibrium partitioning theory (EPT) model assuming linear partitioning to amorphous organic matter (Bucheli and Gustafsson, 2000; Huang et al., 2003; Cornelissen et al., 2004; Cornelissen et al., 2005). Furthermore, a very high sorption capacity, similar or even higher than that of $\mathrm{BC}$, has been previously reported for weathered mineral oil residues for polycyclic aromatic hydrocarbons (PAHs)(Jonker et al., 2003; Brändli et al., 2008) and polychlorinated biphenyls (PCBs) (Cornelissen et al., 2005; McNamara et al., 2005; Jonker and Barendregt, 2006). The sedimentary organic matter heterogeneity, especially the presence of $\mathrm{BC}$ and/or oil fractions, thus significantly affects HOC bioavailability and the risks to the environment (Huang et al., 2003; Cornelissen et al., 2005).

To assess HOC bioavailability, one approach consists of determining the freely dissolved pore water concentrations $\left(\mathrm{C}_{\mathrm{pw}}\right)$ (Reichenberg and Mayer, 2006; Cui et al., 2013). However, trace analysis of HOCs in porewater is a challenging task due to methodological difficulties, such as the separation of the porewater, the adsorption to the sampling equipment, the incomplete phase separation between particle-bound species (i.e., colloids and dissolved organic carbon) and concentrations lower than the detection limit (Hermans et al., 1992; Smedes, 1994; Hawthorne et al., 2009). 
Thus, over the last decade, to overcome these analytical difficulties, methods based on passive sampling techniques have been developed to assess the freely dissolved concentrations of different HOCs in interstitial water (Stuer-Lauridsen, 2005; Allan et al., 2012; Cui et al., 2013). Passive samplers (mainly polymeric phases) are exposed to the sediment of interest, and the $\mathrm{C}_{\mathrm{pw}}$ can then be determined, at equilibrium, from the amount of contaminant accumulated in the sampler. Several devices have been used to determine $\mathrm{C}_{\mathrm{pw}}$ in sediment suspension: solid phase micro extraction (SPME) fibres coated with polydimethylsiloxane (PDMS) (Mayer et al., 2000; Heringa and Hermens, 2003; Cornelissen et al., 2008; Ghosh and Hawthorne, 2010), PDMScoated vials (Reichenberg et al., 2008; Jahnke et al., 2012), polymer strips such as polyoxymethylene (POM) (Jonker and Koelmans, 2001; Cornelissen et al., 2008; Cornelissen et al., 2009), silicone rubber (Smedes et al., 2013) and low density polyethylene (LDPE) (Booij et al., 2003; Lohmann et al., 2005; Tomaszewsky and Luthy, 2008; Fernandez et al., 2009; Friedman et al., 2009; Allan et al., 2012). However, deducing the pore water concentration from passive sampling experiments requires checking various critical points for the validity of the experiment: mainly the attainment of equilibrium (contaminant desorption kinetics are not ratelimiting) and non-depletive conditions (the sorption capacity of the sampler is well below that of the sediment) (Huckins et al., 2006; Reichenberg and Mayer, 2006; Reichenberg et al., 2008). These validation requirements necessitate the selection of adequate sampler size, sediment volume and mixing mode.

The present study aims to determine the pore water concentration of PAHs (16) and PCBs (76) for four French and one Belgian highly contaminated dredged sediment by passive sampling experiments with LDPE strips exposed to saturated sediment under laboratory conditions. The experiments were designed to fulfil the validation requirements cited above. Performance reference compounds (PRC) spiked into the LDPE membranes prior to exposure were used to assess contaminant mass transfer and sediment depletion (Allan et al., 2012; Brand et al., 2012). After elimination of the data not satisfying the validation criteria, the sediment-pore water distribution coefficients $\left(\mathrm{K}_{\mathrm{d}}\right)$ were determined from the ratio of the experimental sediment concentrations $\left(\mathrm{C}_{\mathrm{sed}}\right)$ to the $\mathrm{C}_{\mathrm{pw}}$. The experimental $\mathrm{K}_{\mathrm{d}}$ values were then compared with the theoretical $\mathrm{K}_{\mathrm{d}}$ values obtained from various empirical and mechanistic distribution models used for risk assessments. 


\section{Materials and methods}

2.1. Reagents and glassware. All solvents used for the extractions and analyses (n-hexane, acetone, cyclohexane and methanol) were of SupraSolv grade (Merck, Darmstadt, Germany). Individual analytical recovery standards, internal and PRC standards for the PAHs and PCBs, were obtained from Cluzeau Info Labo (Sainte Foy la Grande, France). The mixture standards (PAH Mix 16, PCB-mix1, PCB-mix 2 and PCB-Mix 3), provided by Dr. Ehrenstorfer Laboratories (Augsburg, Germany), were used for identification and quantification. Purities were $>99.5 \%$ for PAHs and $>99.9 \%$ for the deuterated PAHs. Analytical standards for PCBs were at a purity $>99.3 \%$. Glassware was solvent rinsed and heated overnight in a muffle furnace at 450 ${ }^{\circ} \mathrm{C}$ before use. MilliQ water (Option 15, $\mathrm{Elga}^{\mathrm{TM}}$ ) was used for the PRC spiking into LDPE membranes.

2.2. Sediment sampling sites. The five dredged sediment were collected from contaminated sites across France (Table 1) and were stored in $60 \mathrm{~L}$ barrels. Two of the five sediments were from marine harbours (Marseille and Dunkerque), two were from canals (Lens and Nimy Blaton) and one was from a highway sedimentation tank (Evry). The selected sediments were chosen to present contaminant concentrations higher than the S1 threshold (for fluvial sediment) and the N2 threshold (for marine sediment) according to French regulations on sediment dredging (Decree of August, the $9^{\text {th }}$, 2006) (Table S1). Approximately $1200 \mathrm{~kg}$ (wet weight) of sediment were collected per site. Sediment subsamples were sieved at $2 \mathrm{~mm}$, homogenised and stored at room temperature in the dark before use.

2.3. LDPE strip Preparation. Lay-flat LDPE tubing was purchased from Brentwood Plastics Inc. (St. Louis, USA) and was reproducibly cut along the two side edges, resulting in $2.5 \mathrm{~cm}$ wide LDPE membranes (average membrane thickness of $80 \mu \mathrm{m}$ ). Five centimetre long strips were preextracted twice with cyclohexane for $24 \mathrm{~h}$ and then with methanol for $12 \mathrm{~h}$. The spiking procedure consisted in exposing samplers to a 80:20 methanol/water bath fortified with a series of PRCs under agitation in the dark overnight (Booij et al., 2002). Anthracene- $\mathrm{d}_{10}$, fluoranthene$\mathrm{d}_{10}$, chrysene- $\mathrm{d}_{12}$, benzo[ $[a]$ pyrene- $\mathrm{d}_{12}$, dibenz $[a, h]$ anthracene- $\mathrm{d}_{12}$ and CB-10, CB-14, CB-29, CB-112, and CB-204, were selected for the PAH- and PCB-PRCs, respectively. These 10 PRCs 
covered a $\log \mathrm{K}_{\mathrm{ow}}$ range from 4.53 (anthracene- $\mathrm{d}_{10}$ ) to 7.3 (CB204). For each spiking batch, four strips were randomly sampled and extracted to determine the contamination level. The coefficient of variation $(\mathrm{CV})$ ranged from 3 to $9 \%$ within a batch, depending on the PRC considered. After spiking, the samplers were stored in clean jars at $-20{ }^{\circ} \mathrm{C}$ until use.

2.4. LDPE Exposure in Sediment Slurries. Homogenised samples of saturated sediment were used for laboratory exposition. For each dredged location, seventeen glass jars were filled with 310 to $400 \mathrm{~g}$ of wet sediment (based on the density and water content) and one LDPE strip of $5 \mathrm{~cm}(0.09 \mathrm{~g})$. The mass ratio between the membrane and the total organic carbon (TOC) were on average $0.0064,0.0025,0.0022,0.0028$ and 0.0076, for Marseille, Dunkerque, Lens, Nimy Blaton and Evry, respectively. $\mathrm{C}_{\mathrm{sed}}$ and $\mathrm{C}_{\mathrm{pw}}$ were both determined on the same samples. Exposure jars were closed with PTFE lined caps and placed on a rotating system $(5 \mathrm{rpm})$ for a period of 46 days at $20{ }^{\circ} \mathrm{C}$ in the dark. LDPE strips were regularly sampled for kinetics studies after time periods of 1, 2, 4, 7, 10, 14, 18, 22, 25, 29, 32, 39 and 46 days. Analyses were performed in triplicate for the 14 and 46 day incubation times. For each sediment, unexposed LDPE strips were used as control samplers after 46 days. Control strips were treated according to the same analytical procedures as the exposed strips.

2.5. Analysis of LDPE strips and Sediment characterisation. After exposure, strips were washed with milli-Q water and extracted twice by soaking overnight in $100 \mathrm{~mL}$ cyclohexane. Recovery standards for the PAHs (acenapthene- $\mathrm{d}_{10}$, pyrene- $\mathrm{d}_{10}$, perylene- $\mathrm{d}_{12}$ ) and for the PCBs (CB-30, CB-145, CB-198) were added at the beginning of the first extraction step. Extracts were reduced to $500 \mu \mathrm{L}$ under a gentle stream of nitrogen. Cyclohexane extracts were then combined, and internal standards for PAHs (phenanthrene- $\mathrm{d}_{10}$, indeno[1,2,3-c,d]pyrene- $\mathrm{d}_{12}$ ) and for PCBs (CB-78, Mirex) were added. Sediment characterisation consisted of the determination of the total concentration of PAHs and PCBs and of the oil, total organic and black carbon (BC) contents. For the determination of $\mathrm{PAH}, \mathrm{PCB}$ and the oil content, approximately $3 \mathrm{~g}$ of dry weight homogenised sediment samples were extracted using an accelerated solvent extractor (ASE 350, Dionex). Further information about the analytical methods and quality control / quality assurance can be found in the supplementary material. An overview of the initial characterisation of the five 
tested sediments is given in Table 1. Concentrations of the individual PAH and PCB congeners are given in Tables $\mathrm{S} 2$ and $\mathrm{S} 3$, respectively.

2.6. Non-linear and linear Regression. Non-linear and linear regressions were performed with Sigmaplot version 11 (Scientific computing, USA).

\section{Results and discussion}

3.1. Contaminant Accumulation. A measurable accumulation of PAHs and PCBs into the LDPE membranes was observed for all five sediments. The PAH and PCB concentrations from the control LDPE strips after 46 days of experiment were below detection limits. The accumulation process in the membrane obeys first order kinetics for all of the studied compounds as previously described by Huckins et al. (2006). The concentration in a membrane $\mathrm{C}_{L D P E}$ after a time $(\mathrm{t})$ is expressed in equation 1 :

$$
\mathrm{C}_{\mathrm{LDPE}}(\mathrm{t})=\mathrm{C}_{L D P E}^{e q}\left[1-\exp \left(-\mathrm{k}_{\mathrm{e}} \cdot \mathrm{t}\right)\right]
$$

where $\mathrm{C}_{L D P E}^{e q}\left(\mathrm{ng} \cdot \mathrm{g}^{-1}\right)$ is the concentration in the LDPE strip at equilibrium, and $\mathrm{k}_{\mathrm{e}}\left(\mathrm{d}^{-1}\right)$ is the exchange rate constant. Data from recovery less than $85 \%$ and greater than $115 \%$ were ruled out. Approximately $7 \%$ and $9 \%$ of the data points had to be deleted for this reason for PAHs and PCBs, respectively.

The uptake curves fitted correctly with equation 1 with significant coefficients of determination for all contaminants (Fig. S1 for PAHs and Fig. S2 for PCBs). Triplicate analyses at day 14 and 46 showed good reproducibility with a relative standard deviation lower than 9 or $11 \%$ for PAHs and PCBs, respectively. The exchange rates between the LDPE strips and water were calculated from equation 1 for each contaminant. Most of the contaminants (92\% and $96 \%$ of PAHs and PCBs, respectively) had reached the equilibrium state after 46 days. Similar uptake curves have been previously reported by various authors (Booij et al., 2003; Allan et al., 2012; Smedes et al., 2013). After 46 days, the highest accumulated amounts of PAHs were found in LDPE membranes exposed to Lens sediment, whereas the lowest were for the Evry sediment. This result is correlated with the total sediment contamination level (Table 1). 
As illustrated in Fig. 1 for the Lens sediment, the estimated exchange rate constant $\mathrm{k}_{\mathrm{e}}$ is significantly correlated to the hydrophobicity of the compounds represented here by the logarithm of their octanol-water partition coefficient $\left(\log \mathrm{K}_{\mathrm{ow}}\right)$ for both native contaminants and PRCs. The highest rates of dissipation were observed for the most hydrophobic compounds (i.e., dibenz $[a, h]$ anthracene for PAHs and CB-180 for PCBs). The exchange rate constants for the added PRCs and for the native contaminants are on the same order of magnitude. Similar results were obtained by Booij et al. (2003) and Allan et al. (2012) with LDPE strips exposed to harbour contaminated sediment. For an identical $\log \mathrm{K}_{\mathrm{ow}}$, higher exchange rate constant values were observed for PCBs, in comparison with PAHs, as illustrated by Fig. 1 for the Lens sediment and by Fig. S3 for the four other sediments. This difference could be explained by higher solubilities and differences in sorption mechanisms and interactions with the different sediment phases, as well as different diffusion coefficients in the LDPE membrane. Recently, Rusina et al. (2010) have shown strong relations between the logarithm of the diffusion coefficient (D) and MW: for a given MW, higher diffusion coefficients were found for PCBs than for PAHs, confirming that the structure of the organic compounds affects the diffusion in the polymers.

3.2. PRC exchange rate constants. For each sediment, logarithms of the PRC dissipation rate $\log \mathrm{k}_{\mathrm{e}}\left(\mathrm{d}^{-1}\right)$ values were plotted as a function of $\log \mathrm{K}_{\mathrm{ow}}$ in Fig. 2 for PAHs and Fig. S4 for PCBs. The values obtained in this study were comparable to those reported for PRC by Booij et al. (2003) and Allan et al. (2012). Differences in the $\log \mathrm{k}_{\mathrm{e}}$ values could be seen between the five sediments despite incubation under similar conditions. The highest $\log \mathrm{k}_{\mathrm{e}}$ values were observed for Evry sediment for both PAHs and PCBs. The PRC exchange rate constants increased in the order of Nimy Blaton < Marseille < Lens < Dunkerque < Evry for both PAHs and PCBs. Recently, Smedes et al. (2013) have shown that the sediment content in suspension had a large influence on the uptake rate. According to those authors, the uptake rate increased with sediment content. In our study, the sediment concentrations were quite similar for all the five sediment and ranged from 0.40 (Lens) to 0.46 (Evry) g of sediment per g of suspension. The slight difference between sediment suspensions may explain the higher exchange rate constant observed for Evry. However, this parameter cannot explain the lower exchange rate constant observed for Nimy Blaton. Additionally, according to Booij et al. (2003), when resistance to the contaminant mass transfer into the membrane is much more related to the boundary layer process rather to the sampler itself, differences in the exchange rate constant could be the result of the sorption 
properties of the sediment (particle size, porosity, TOC, BC, oil content). The highest $\log \mathrm{k}_{\mathrm{e}}$ values were indeed observed for the Evry sediment, which was characterised by a sandy texture with a low organic carbon content (Table 1). On the other hand, Nimy Blaton presented the lowest $\log \mathrm{k}_{\mathrm{e}}$ values, characterised by a clayed-silt texture with high organic carbon content.

3.3. Depletion monitoring using Performance Reference Compounds. According to Booij et al. (2003), to avoid contaminant depletion in sediment, two critical conditions regarding the experimental design should be met. The first one was that the buffering capacity of the sediment needs to be sufficient to ensure constant aqueous concentrations. In this respect, the contaminant amounts extracted from the sediment phase should be small compared with the initial amounts $(<$ $1 \%)$. The same authors proposed reducing the risk that the HOC desorption from the sediment suspension becomes rate-limiting by constraining the system to an LDPE/TOC mass ratio below $0.05 \mathrm{~g} . \mathrm{g}^{-1}$. In other words, a ratio below $0.05 \mathrm{~g} \cdot \mathrm{g}^{-1}$ would minimise contaminant depletion in the sediment as a result of absorption into the LDPE during sampler exposure. The present experiment was thus designed to fulfil both requirements, i.e., the absorbed amounts were lower than $1 \%$ of the total quantity in the slurry for both PAHs and PCBs and the LDPE/TOC ratios were at least six times lower than $0.05 \mathrm{~g} \cdot \mathrm{g}^{-1}$.

Deducing the pore water concentration from this type of experiments requires checking whether a non-depletive situation was really obtained for the selected passive sampler. For that purpose, the sorption capacity of the sampler has to be negligible in comparison with that of the sediments. The depletion was monitored by the use of PRCs as proposed by Brand et al. (2012). If the sorption capacity of the sampler is negligible in comparison with that of the sediment, PRCs will release completely from the sampler. An incomplete release from samplers will indicate either that the equilibrium was not achieved or that the sediment phase was depleted. A distribution factor (DF) corresponding to the ratio of the amount of PRCs remaining in the membrane and the amount of PRCs in the sediment at equilibrium was calculated for all the PRCs in each exposure condition:

$$
\mathrm{DF}=\mathrm{C}_{L D P E}^{P R C, e q} / \mathrm{C}_{S e d}^{P R C, e q}
$$


The DF values ranged from less than 0.02 for fluoranthene-D10 (Marseille sediment) to 1.68 for CB-204 (Evry sediment).

When the DF value is 0.1 or less, the sampler's sorption capacity is very small compared to that of the sediment. Consequently, the measured $\mathrm{C}_{\mathrm{pw}}$ will not be significantly affected by the depletion of analytes in the sediment. In contrast, a higher DF value means that there is a small sorption capacity in the sediment and it is likely that the sampler has extracted a substantial fraction of the sediment's analytes and that the calculated $\mathrm{C}_{\mathrm{pw}}$ value does not represent the "true" value (Brand et al., 2012). In such a case, the $C_{p w}$ will be underestimated. For CB-204, we observed high distribution factors for NB and Evry, 0.99 and 1.68, respectively. In our experimental conditions, using LDPE strips, the exponential increase of DF with the $\log \mathrm{K}_{\mathrm{ow}}$ could not be explained by a non-equilibrium state but rather by the result of both the sediment and membrane properties. High DF values mean that the sorption capacity in the sediment is lower than the one of the sampler and probably indicates that the membrane material has depleted the sediment (Brand et al. 2012). Additionally, very low diffusion coefficients in the LDPE membranes could also control the dissipation stage, especially for high molecular weight PRCs, and induce apparent equilibrium status (Rusina et al., 2007).

3.4. Quality control of the data. From the experimental PRC DF values and for each sediment, using DF=f(log $\left.\mathrm{K}_{\mathrm{ow}}\right)$ exponential regression models (Fig. S5), we calculated the DF values for all contaminants. We decided to keep data when the DF values were 0.1 or less for PAHs and 0.3 or less for PCBs. An underestimation of the pore water concentration by a maximum factor of 1.3 could be expected for PCBs. According to these requirements, data for PAHs with $\log \mathrm{K}_{\mathrm{ow}}<6.75$ were conserved for the five sediments. In the same way, PCBs with $\log \mathrm{K}_{\mathrm{ow}}<7.11$ were conserved for all sediments except for Evry, where the PCB data were considered for congeners with $\log \mathrm{K}_{\mathrm{ow}}<6.92$. The difference observed for this latter sediment could be due both to the poor native concentration of PCBs and to its "sandy" structure associated with a low content of condensed organic carbon phase (Table 1). Consequently, in accordance with our "acceptance rule", approximately $20 \%$ of the data points were not considered for the further work.

3.5. Freely Dissolved Porewater Concentration. Taking into account these validation requirements, $\mathrm{C}_{\mathrm{pw}}$ values were then determined from the LDPE concentrations at equilibrium 
according to equation 1 . For the present work, the $\log \mathrm{K}_{\mathrm{LDPE}-w a t e r}$ values for both PAHs and PCBs were calculated from MW according to Smedes et al. (2009), taking into account the chlorine position for PCBs.

The ranges of freely dissolved concentrations of PAHs and PCBs are presented in Table S4. For PAHs, $\mathrm{C}_{\mathrm{pw}}$ ranged from $0.006 \mathrm{ng} . \mathrm{L}^{-1}$ for dibenz $[a, h]$ anthracene to $584.3 \mathrm{ng} . \mathrm{L}^{-1}$ for naphthalene. For PCBs, the $\mathrm{C}_{\mathrm{pw}}$ values were lower, ranging from $0.006 \mathrm{ng} . \mathrm{L}^{-1}$ to $2.77 \mathrm{ng} . \mathrm{L}^{-1}$, respectively for CB-180 and CB-52. The concentrations of the present study were in the same range of magnitude of the values reported in the literature (Booij et al., 2003; Tomaszewsky and Luthy, 2008; Hawthorne et al., 2011; Allan et al., 2012). The sum of the freely dissolved PAH (14) concentrations increased in the following order: Evry < Dunkerque < Marseille < Nimy Blaton < Lens. Approximately $80 \%$ of the total freely dissolved concentrations of PAHs were represented by the two and three aromatic ring congeners (Fig. S6). Among the various congeners, naphthalene accounted for more than $60 \%$ of the dissolved PAHs, excepted for in the Lens sediment. The sum of the freely dissolved PCB (76) concentrations increased in the following order: Nimy Blaton < Lens < Dunkerque < Evry < Marseille. Although less abundant in the sediments, 3- and 4-Cl PCBs were responsible for more than $52 \%$ of the total dissolved PCBs (Fig. S7).

3.6. Distribution coefficients $\mathbf{K}_{\mathbf{d}}$ and $\mathbf{K}_{\text {TOC. }}$ From the validated pore water concentrations $\left(\mathrm{C}_{p w}^{E q}\right)$ and contaminant sediment concentrations $\left(\mathrm{C}_{\text {sed }}^{E q}\right)$ at equilibrium, we calculated the experimental $\mathrm{K}_{\mathrm{d}}$ and $\mathrm{K}_{\mathrm{TOC}}$ (total organic carbon-normalised distribution coefficients), according to equations 3 and 4.

$$
\begin{gathered}
\mathrm{K}_{\mathrm{d}, \exp }\left(\mathrm{L}_{\mathrm{pw}} \cdot \mathrm{kg}^{-1}\right)=\left(\mathrm{C}_{\text {sed }}^{E q} / \mathrm{C}_{p w}^{E q}\right) \\
\mathrm{K}_{\mathrm{TOC}}\left(\mathrm{L}_{\mathrm{pw}} \cdot \mathrm{kg}_{\mathrm{TOC}}{ }^{-1}\right)=\mathrm{C}_{\text {sed }}^{E q} /\left(\mathrm{C}_{p w}^{E q} \cdot \mathrm{f}_{\mathrm{TOC}}\right)
\end{gathered}
$$

We compared our experimental $\log \mathrm{K}_{\mathrm{TOC}}$ values to the literature values from twelve references for PAHs and six references for PCBs. The $\mathrm{K}_{\mathrm{TOC}}$ values obtained for the PAHs and PCBs by our method (LDPE) were consistent with the literature, with the $\log \mathrm{K}_{\mathrm{TOC}}-\log \mathrm{K}_{\mathrm{ow}}$ linear regressions 
resulting in slopes close to 1 for both compound families (Fig. S8 for PAHs and Fig. S9 for PCBs).

Subsequently, we compared our observations of sediment-pore water partitioning to equilibrium expectations based on the sediment organic carbon content, assuming the well-documented relationship $\mathrm{K}_{\mathrm{d}}=\mathrm{f}_{\mathrm{TOC}} \cdot \mathrm{K}_{\mathrm{TOC}}$. The $\log \mathrm{K}_{\mathrm{TOC}}$ of the PAHs and PCBs were calculated by the correlation with the $\log \mathrm{K}_{\mathrm{ow}}$ established by Schwarzenbach et al. (2003). The $\log \mathrm{K}_{\mathrm{d} \text {,exp }}$ values observed were systematically higher than the calculated values from $\log \mathrm{K}_{\mathrm{ow}}$. The divergence of the $\log \mathrm{K}_{\mathrm{d} \text { exp }}$ values were highest for PAHs (1.5 - $1.9 \log$ unit). The $\mathrm{K}_{\mathrm{d} \text {,exp }}$ values for the PCBs were higher than the calculated values by approximately $1 \log$ unit. As previously reported (Cornelissen et al., 2005; Allan et al., 2012), adsorption by total organic carbon ( $\mathrm{f}_{\mathrm{TOC}} \mathrm{K}_{\mathrm{TOC}}$ ) is not sufficient to explain the sorption of native organic contaminants in these five sediments. These findings highlight the need to consider the nature of the sedimentary organic matter and, in particular, to distinguish the different phases presenting different sorption capacities.

3.7. Partitioning model and experimental $\mathbf{K}_{\mathbf{d}}$ values. Currently, two types of partitioning models are used in the literature to describe the sorption capacity of the sediment: (i) mechanistic approaches mainly by accounting for the contribution of all sorbents, and (ii) empirical approaches mainly by accounting for physicochemical properties of the contaminant and sorption properties of one specific BC selected phase (coal tar, activated carbon) (Arp et al., 2009).

For mechanistic approaches, the distributions of HOCs were evaluated using the double and triple domain sorption model (Eq. 5 and 6).

$$
\begin{aligned}
& K d=f_{A O C} \cdot K_{A O C}+f_{B C} \cdot K_{B C} \cdot C_{p w}{ }^{n-1}(5) \\
& K d=f_{A O C} \cdot K_{A O C}+f_{O i l} \cdot K_{O i 1}+f_{B C} \cdot K_{B C} \cdot C_{p w}{ }^{n-1}(6)
\end{aligned}
$$

in which $f_{\mathrm{AOC}}\left(\mathrm{f}_{\mathrm{AOC}}=\mathrm{f}_{\mathrm{TOC}}-\mathrm{f}_{\mathrm{BC}}\right), f_{\mathrm{oil}}$, and $f_{\mathrm{BC}}$ are the amorphous organic carbon, oil, and black

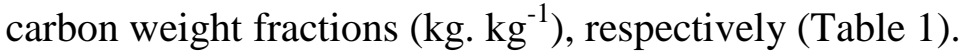

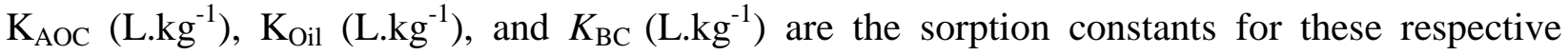
phases. The model described in Eq.6, recently proposed by Koelmans et al. (2009), takes into account the high sorption capacity of weathered oil. According to Jonker et al. (2003), oil can behave as an additional sorbent when the oil content approximates 10 to $30 \%$ of the total organic carbon weight basis (corresponding to the Critical Separate Phase Concentration - CSPC). For the 
studied sediment, the mass ratio between the oil and TOC content ranged from $6 \%$ to $14 \%$ for NB and Evry (Table 1). The triple domain sorption model was thus applied for the sediment from Marseille, Dunkerque and Evry with respective oil/TOC ratios of $11 \%, 11 \%$ and $14 \%$.

The sorption distribution coefficients considered for each model were calculated from compoundclass specific regressions with $\log K_{\mathrm{ow}}$. $\log \mathrm{K}_{\mathrm{AOC}}$ values were calculated according to Schwarzenbach et al. (2003), and $\log \mathrm{K}_{\mathrm{BC}}$ or $\log \mathrm{K}_{\text {Oil }}$ were calculated from the $\log \mathrm{K}_{\mathrm{ow}}$ (Eq. 7 to 14), as presented in Table 2. The chromatographic analysis of the aliphatic hydrocarbons in all sediment revealed an advanced state of oil degradation with the presence of large unresolved complex mixtures (UCMs) (Wang et al., 2011). Therefore, we considered $\mathrm{K}_{\text {oil }}$ values for weathered oil (Eq. 9, 10 and 14). The Freundlich exponent (n) for nonlinear sorption to BC was set to 0.7 for PAHs (Eq. 7 and Eq. 8) as proposed by Hawthorne et al. (2007) and Koelmans et al.(2009). For PCBs, n was also set to 0.7 (Eq. 12 and Eq. 13), as previously reported by several authors (Accardi-Dey and Gschwend, 2002; Moermond et al., 2005; Pikaar et al., 2006; Koelmans et al., 2009) and to 1 (linear sorption isotherm), as proposed by Werner et al. (2010), for equation 11 .

For the empirical approach, we tested the "coal tar model", considered as the most appropriate polyparameter linear free-energy relationship (PP-LFER) based on the Abraham's solvation parameters (Arp et al., 2009; van Noort et al., 2010). Additionally, we also compared our set of data to the Raoult's Law model, using coal tar as the sorbent phase. For PCBs, and for both models, we added a specific term based on the abundance ratio of the PCB congeners (WF), as a proxy for weathering, aiming for a better correlation (Hawthorne et al., 2011). WF ranged from 0 to near 1, respectively, for fresh to weathered contamination. From experimental concentrations of CB 28, 52 and 153, we obtained WF of 0.60, 0.75, 0.83, 0.86 and 0.96, for Evry, NB, Lens, Dunkerque and Marseille sediment, respectively.

Experimental data from Marseille, Dunkerque and Evry sediment were tested with the double and triple domain sorption model, whereas Lens and NB were tested with the double domain sorption model for the validation of the best combination among equations 7 to 14 in Table 2. All experimental data were tested with both empirical models. Models were considered successful for the prediction of average $\log \mathrm{K}_{\mathrm{d}}$ or $\log \mathrm{K}_{\mathrm{TOC}}$ when $90 \%$ and $99 \%$ of the computed values were 
contained in the respective ranges of $\pm 1 \log$ (factor \pm 10 ) and of $\pm 1.5 \log$ (factor of \pm 30 ) (Arp et al., 2009; Hawthorne et al., 2011).

For PAHs, among the tested models, the best results were obtained for empirical models and particularly for Raoult's Law model (Fig. 3). This model predicted $\log \mathrm{K}_{\mathrm{TOC}}$ values in the ranges of $\log \pm 1$ and \pm 1.5 with frequencies of $91 \%$ and $100 \%$, respectively. The mean deviation was $0.39( \pm 0.52)$, showing on average a slight underestimation of $\log \mathrm{K}_{\mathrm{TOC}}$. The $K_{\text {Oil }}$ values for the PAHs were estimated using a $\log K_{\text {Oil }}-\log K_{\text {ow }}$ regression (Eq. 9) for compounds presenting $\log$ $\mathrm{K}_{\mathrm{ow}}$ ranging from 4.6 to 6.9 , as previously described by Koelmans et al. (2009). Considering this $\log \mathrm{K}_{\text {ow }}$ range, the $\mathrm{K}_{\mathrm{d}}$ experimental values were properly predicted by the triple domain sorption model (Eq. 6) using Eq. 7 and Eq. 9 (Table 2). The slope of the linear regression log $\mathrm{K}_{\mathrm{d} \text {,pred }}-\log$ $\mathrm{K}_{\mathrm{d} \text {,exp }}$ was close to 1 , and all the computed values were contained in a range of $\pm 1 \log$ (factor of 10) (Fig.S10). From this mechanistic approach, it was possible to evaluate the PAH sorption to different organic phases of the sediment. As illustrated for the Lens sediment in Fig. S11, the less hydrophobic PAHs were preferentially sorbed to the oil fraction, whereas the most hydrophobic PAHs were mainly sorbed to BC.

On the other hand, the mechanistic model exhibited better results for PCBs (Eq. 6) with estimation of $\mathrm{K}_{\mathrm{BC}}$ from Eq. 12 and $\mathrm{K}_{\mathrm{Oil}}$ from Eq. 14 for the Marseille, Dunkerque and Evry sediments. As illustrated for the Lens sediment in Fig. S11, PCB congeners were mainly sorbed to $\mathrm{BC}$ (up to $50 \%$ ), and the oil fraction accounted for 10 to $30 \%$ of sorption, depending on the congeners.

Although the ratio for the NB and Lens sediments were lower than the supposed CSPC values discussed above, the triple domain sorption model was successfully applied to the Lens and Nimy Blaton sediment, which also presented important oil contents $\left(6310\right.$ and $9580 \mathrm{mg} \cdot \mathrm{kg}^{-1}$, respectively). The observed values were all included in the factors of 10 (Fig. 3). This approach presented a significant correlation with the experimental values $\left(R^{2}=0.69\right)$ with a deviation on average of $0.12 \pm 0.33$. Experimental distribution coefficients for the PCB values for the NB and Lens sediments were well-described by the triple domain sorption, despite an oil/TOC mass ratio lower than the CSPC values. These findings could be explained by the fact that the CSPC value was determined by Jonker et al. (2003) for a unique oil-spiked and weathered sediment with a 
low organic content $(<1 \%)$. The behaviour of real decades-weathered sediment could be notably different in terms of native contaminant desorption (Chai et al., 2006). In fact, the presence of separate phases would be a function of the oil content but also of the type and the amount of organic carbon (Jonker and Barendregt, 2006) and the presence of clay-humic complexes (Lu et al., 2006). This reveals the need for a better assessment of the CSPC value used to define the applicability limits of the model. The different types of organic carbon must be taken into account. To this end, the molecular weight could give some valuable information. Thus, a better estimation of the CSPC could be achieved by using molar-based in place of mass-based values. This calls for further work in this domain.

\section{Conclusion}

Passive sampling with LDPE strips is suitable for measuring the pore water concentrations and assessing the sorption capacity (sediment/pore water distribution coefficient) of various contaminated sediments. For the studied compounds, in view of an operational approach (risk assessment/remediation), it was difficult to use a predictive model to determine $\mathrm{C}_{\mathrm{pw}}$ because of the large number of literature models (both empirical and mechanistic) and regressions (choice of the partitioning coefficient for a specific sorbent phase). Nevertheless, acceptable correlations between model predictions and experimental data were obtained for five different and distinct sediments. Reliable predictive relationships for PAH partitioning were obtained by Raoult's Law model using the physicochemical properties of each contaminant (water solubility) and coal tar sorbent phase concentration. For PCBs, triple domain sorption (amorphous organic carbon, black carbon and oil phases) could model the data successfully. The differences observed for the PCB phase distribution in the five sediments could be explained by the type and source of the organic matter. Nevertheless, particularly under a regulatory framework, it is important to obtain a more reliable estimation of CSPC to better assess the applicability limits of the triple domain sorption model. To this end, and to improve the robustness of both models, substantial additional work is required. Moreover, in most cases, the use of such models implies a thorough knowledge of the sediment composition. Although, to date, no analytical consensus was found for the choice of a 
specific method for the determination of the porewater concentration, the direct measurement seems to be more accurate and thus, preferable.

\section{Acknowledgements}

We acknowledge financial support from GEDSET INTERREG, FR ECOREV and PhD granting from the Provence-Alpes-Côte d'Azur Region (France).

\section{Appendix A. Supplementary information}

Quality threshold values for dredging according to the French regulation for PAH and PCB, PCB and PAH sediment concentrations for all sediments; accumulation of five PAHs and PCBs in LDPE membrane exposed to Lens sediment; correlation between the exchange rate constant $\left(\log \mathrm{k}_{\mathrm{e}}\right)$ with the molecular weight for the five contaminated sediments for PAHs; the first-order dissipation rate constant $\left(\log \mathrm{k}_{\mathrm{e}}\right.$ ) of PCB PRCs into LDPE membrane samplers for the five sediments; the distribution factor for PAH PRCs and PCB PRCs as a function of $\log \mathrm{K}_{\mathrm{ow}}$ for Lens sediment; the ranges of pore water concentrations for the studied PAHs and the seven indicator PCBs; the fingerprint of the PAHs and PCBs concentrations in pore water and in sediment; positioning $\log \mathrm{K}_{\mathrm{TOC}}$ values for PAHs and PCBs for the five sediments among the $\log \mathrm{K}_{\mathrm{TOC}}$ values from literature; the triple sorption model correlation for PAHs and the PAHs and PCBs distribution among AOM, BC and Oil sorbent phases are available in the supporting information.

\section{References}

Accardi-Dey, A., Gschwend, P.M., 2002. Assessing the Combined Roles of Natural Organic Matter and Black Carbon as Sorbents in Sediments. Environmental Science \& Technology 36, 21-29.

Allan, I.J., Ruus, A., Schaanning, M.T., Macrae, K.J., Næs, K., 2012. Measuring nonpolar organic contaminant partitioning in three Norwegian sediments using polyethylene passive samplers. Science of the Total Environment 423, 125-131.

Arp, H.P.H., Breedveld, G.D., Cornelissen, G., 2009. Estimating the in situ sediment-porewater distribution of PAHs and chlorinated aromatic hydrocarbons in anthropogenic impacted sediments. Environmental Science \& Technology 43, 5576-5585.

Booij, K., Hoedemaker, J.R., Bakker, J.F., 2003. Dissolved PCBs, PAHs, and HCB in Pore Waters and Overlying Waters of Contaminated Harbor Sediments. Environmental Science \& Technology 37, 42134220 . 
Booij, K., Smedes, F., Van Weerlee, E.M., 2002. Spiking of performance reference compounds in low density polyethylene and silicone passive water samplers. Chemosphere 46, 1157-1161.

Brand, E., Smedes, S., Jonker, M.T.O., Harmsen, J., Peijnenburg, W.J.G.M., Lijzen, J.P.A., 2012. Advice on implementing bioavailability in the Dutch soil policy framework - User protocols for organic contaminants. RIVM report 711701102, 73.

Brändli, R.C., Hartnik, T., Henriksen, T., Cornelissen, G., 2008. Sorption of native polyaromatic hydrocarbons (PAH) to black carbon and amended activated carbon in soil. Chemosphere 73.

Bucheli, T.D., Gustafsson, Ö., 2000. Quantification of the sootwater distribution coefficient of PAHs provides mechanistic basis for enhanced sorption observations. Environmental Science \& Technology 34, 5144-5151.

Chai, Y., Kochetkov, A., reible, D.D., 2006. Desorption resistance of polycyclic aromatic hydrocarbons and duration of exposure. Environmental Toxicology and Chemistry 25, 2827-2833.

Cornelissen, G., Arp, H.P.H., Pettersen, A., Hauge, A., Breedveld, G.D., 2008. Assessing PAH and PCB emissions from the relocation of harbour sediments using equilibrium passive samplers. Chemosphere 72 , 1581-1587.

Cornelissen, G., Gustafsson, O., Bucheli, T.D., Jonker, M.T.O., Koelmans, A.A., Van Noort, P.C.M., 2005. Extensive sorption of organic compounds to black carbon, coal, and kerogen in sediments and soils : Mechanisms and consequences for distribution, bioaccumulation, and biodegradation. Environmental Science \& Technology 39, 6881-6895.

Cornelissen, G., Kukulska, Z., Kalaitzidis, S., Christanis, K., Gustafsson, Ö., 2004. Relations between Environmental Black Carbon Sorption and Geochemical Sorbent Characteristics. Environmental Science \& Technology 38, 3632-3640.

Cornelissen, G., Okkenhaug, G., Breedveld, G.D., Sørlie, J.E., 2009. Transport of PAHs and PCBs in a landfill: a novel passive sampler to determine free and total dissolved concentrations in leachate water. Journal of Hydrology 369, 253-259.

Cui, X., Mayer, P., Gan, J., 2013. Methods to assess bioavailability of hydrophobic organic contaminants: Principles, operations, and limitations. Environmental Pollution 172, 223-234.

Fernandez, L.A., Macfarlane, J.K., Tcaciuc, A.P., Gschwend, P.M., 2009. Measurement of Freely Dissolved PAH Concentrations in Sediment Beds Using Passive Sampling with Low-Density Polyethylene Strips. Environmental Science \& Technology 43, 1430-1436.

Friedman, C., Burgess, R.M., Perron, M.M., Cantwell, M.G., Ho, K.T., Lohmann, R., 2009. Comparing polychaete bioaccumulation and passive sampler uptake to assess the effects of sediment resuspension on PCB bioavailability. Environmental Science \& Technology 43, 2865-2870.

Ghosh, U., Hawthorne, S.B., 2010. Particle-scale measurement of PAH aqueous equilibrium partitioning in impacted sediments. Environmental Science \& Technology 44, 1204-1210.

Hawthorne, S. B.; Grabanski, C. B.; Miller, D. J., 2007. Measured partition coefficients for parent and alkyl polycyclic aromatic hydrocarbons in 114 historically contaminated sediments: Part 2. Testing the $\mathrm{K}_{\mathrm{OC}} \mathrm{K}_{\mathrm{BC}}$ two carbon-type model. Environmental Toxicology and Chemistry 26, 2505-2516. 
Hawthorne, S.B., Grabanski, C.B., Miller, D.J., 2009. Solid-phase-microextraction measurement of 62 polychlorinated biphenyl congeners in milliliter sediment pore water samples and determination of $\mathrm{K}_{\mathrm{DOC}}$ values. Analytical Chemistry 81 6936-6943.

Hawthorne, S.B., Grabanski, C.B., Miller, D.J., Arp, H.P.H., 2011. Improving predictability of sediment porewater partitioning models using trends observed with PCB-contaminated field sediments. Environmental Science \& Technology 45, 7365-7371.

Heringa, M.B., Hermens, J.L.M., 2003. Measurement of free concentrations using negligible depletionsolid phase microextraction (nd- SPME). Trends in Analytical Chemistry 22, 575-587.

Hermans, J.H., Smedes, F., Hofstraat, J.W., Cofino, W.P., 1992. A method for estimation of chlorinated biphenyls in surface waters: influence of sampling method on analytical results. Environmental Science \& Technology 26, 2028-2034.

Huang, W., Peng, P.A., Yu, Z., Fu, J., 2003. Effects of organic matter heterogeneity on sorption and desorption of organic contaminants by soils and sediments. Applied Geochemistry, 955-972.

Huckins, J.N., Petty, J.D., Booij, K., 2006. Monitors of organic chemicals in the environment. In: semipermeable membrane devices. Springer, New-York.

INERIS, 2009. Impacts sur les milieux aquatiques des sédiments de dragage gérés à terre : Problématique, contexte réglementaire, modélisation du transfert de contaminants organiques. $\mathrm{N}^{\circ} \mathrm{DRC}-08-95306-16457 \mathrm{~A}$, p64.

Jahnke, A., Mayer, P., McLachlan, M.S., 2012. Sensitive equilibrium sampling to study polychlorinated biphenyl disposition in baltic sea sediment. Environmental Science \& Technology 46, 10114-10122.

Jonker, M.T.O., Barendregt, A., 2006. Oil is sedimentary supersorbent for PolyChlorinated Biphenyls. Environmental Science \& Technology 40, 3829-3835.

Jonker, M.T.O., Koelmans, A.A., 2001. Polyoxymethylene solid phase extraction as a partitioning method for hydrophobic organic chemicals in sediments and soot. Environmental Science \& Technology 35, 3742-3748.

Jonker, M.T.O., Sinke, A.J.C., Brils, J.M., Koelmans, A.A., 2003. Sorption of Polycyclic Aromatic Hydrocarbons to oil contaminated sediment: unresolved complex? Environmental Science \& Technology 37, 5197-5203.

Koelmans, A.A., Jonker, M.T.O., Cornelissen, G., Bucheli, T.D., Van Noort, P.C.M., Gustafsson, O., 2006. Black carbon: The reverse of its dark side. Chemosphere 63, 365-377.

Koelmans, A.A., Kaag, K., Sneekes, A., Peeter, E.T.H.M., 2009. Triple Domain in Situ Sorption Modeling of Organochlorine Pesticides, Polychlorobiphenyls, Polyaromatic Hydrocarbons, Polychlorinated Dibenzo-p-Dioxins, and Polychlorinated Dibenzofurans in Aquatic Sediments. Environmental Science \& Technology 43, 8847-8853.

Lohmann, R., MacFarlane, J.K., Gschwend, P.M., 2005. Importance of black carbon to sorption of native pahs, pcbs, and pcdds in boston and new york, harbor sediments. Environmental Science \& Technology $39,141-148$. 
Lu, X., Reible, D.D., Fleeger, J.W., 2006. Bioavailability of polycyclic aromatic hydrocarbons in fieldcontaminated Anacostia River (Washington, DC) sediment. Environmental Toxicology and Chemistry 25, 2869-2874.

Mayer, P., Vaes, W.H.J., Hermens, J.L.M., 2000. Absorption of Hydrophobic Compounds into the Poly(dimethylsiloxane) Coating of Solid-Phase Microextraction Fibers: High Partition Coefficients and Fluorescence Microscopy Images. Analytical Chemistry 72, 459-464.

McNamara, S.W., Ghosh, U., Dzombak, D.A., Weber, A.S., Smith, J.R., Luthy, R.G., 2005. Effect of oil on polychlorinated biphenyl phase partitioning during land biotreatment of impacted sediment. Journal of Environmental Engineering 131, 278-286.

Moermond, C.T.A., Zwolsman, J.J.G., Koelmans, A.A., 2005. Black carbon and ecological factors affect in situ biota to sediment accumulation factors for hydrophobic organic compounds in flood plain lakes. Environmental Science \& Technology 29, 3101-3109.

Pikaar, I., Koelmans, A.A., Van Noort, P.C.M., 2006. Sorption of organic compounds to activated carbons. Evaluation of isotherm models. Chemosphere 65, 2343-2351.

Reichenberg, F., Mayer, P., 2006. Two complementary sides of bioavailability: accessibility and chemical activity of organic contaminants in sediments and soils. Environmental Toxicology and Chemistry 25, $1239-1245$.

Reichenberg, F., Smedes, F., Jonsson, J.A., Mayer, P., 2008. Determining the chemical activity of hydrophobic organic compounds in soil using polymer coated vials. Chemistry Central Journal, 1-10.

Rusina, T.P., Smedes, F., Klanova, J., Booij, K., Holoubek, I., 2007. Polymer selection for passive sampling: A comparison of critical properties. Chemosphere 68, 1344-1351.

Schwarzenbach, R. P.; Gschwend, P. M.; Imboden, D. M. Environmental Organic Chemistry , 2nd ed.; JohnWiley \& Sons: Hoboken, 2003; pp 1313.

Smedes, F., 1994. Sampling and partition of neutral organic contaminants in surface waters with regard to legislation, environmental quality and flux estimations. International Journal of Environmental Analytical Chemistry 57, 215-229.

Smedes, F., Geertsma, R. W., van der Zande, T., Booij, K., 2009. Polymer-water partition coefficients of hydrophobic compounds for passive sampling: application of cosolvent models for validation.

Environmental Science \& Technology 43, 7047-7054

Smedes, F., Alexander van Vliet, L., Booij, K., 2013. Multi-Ratio Equilibrium Passive Sampling Method to Estimate Accessible and Pore Water Concentrations of Polycyclic Aromatic Hydrocarbons and Polychlorinated Biphenyls in Sediment. Environmental Science \& Technology, 47, 510-517

Stuer-Lauridsen, F., 2005. Review of passive accumulation devices for monitoring organic micropollutants in the aquatic environment. Environmental Pollution 136, 503-524. 
Tomaszewsky, J.E., Luthy, R.G., 2008. Field Deployment of Polyethylene Devices to Measure PCB Concentrations in Pore Water of Contaminated Sediment. Environmental Science \& Technology 42, 6086-6091.

van Noort, P.C.M., Haftka, J.J.H., Parsons, J.R., 2010. Updated abraham solvation parameters for polychlorinated biphenyls. Environ Sci Technol 44, 7037-7042.

Wang, C., Du, J., Gao, X., Duan, Y., Sheng, Y., 2011. Chemical characterization of naturally weathered oil residues in the sediment from Yellow River Delta, China. Marine Pollution Bulletin 62, 2469-2475.

Werner, D., Hale, S.E., Ghosh, U., Luthy, R.G., 2010 - Polychlorinated biphenyl sorption and availability in field-contaminated sediments. Environmental Science \& Technology 44, 2809-2815 


\title{
Polyethylene passive samplers to determine sediment-porewater distribution coefficients of persistent organic pollutants in five heavily contaminated dredged sediment
}

\author{
Benoit Charrasse, Céline Tixier, Pierre Hennebert and Pierre Doumenq
}

\section{LIST OF TABLES}

Table 1. Initial characterization of the five tested sediments including: black carbon (BC) and total organic carbon (TOC) content; contaminant concentration; total hydrocarbons content (Oil) and texture.

Table 2. Relationships between $\mathrm{K}_{\mathrm{BC}}, \mathrm{K}_{\mathrm{oil}}$ and $\mathrm{K}_{\mathrm{ow}}$ for PAHs and PCBs. 
Table 1. Initial characterization of the five tested sediments including: black carbon (BC) and total organic carbon (TOC) content; contaminant concentration; total hydrocarbons content (Oil) and texture.

\begin{tabular}{|c|c|c|c|c|c|c|}
\hline & Unit & Evry & Dunkerque & Lens & Marseille & Nimy Blaton \\
\hline Origin & & $\mathrm{HST}^{1}$ & Marine harbor & Canal & Marine harbor & Canal \\
\hline \multirow{2}{*}{ Localization } & & $48^{\circ} 36^{\prime} 34.99^{\prime \prime} \mathrm{N}$ & $51^{\circ} 2{ }^{\prime} 33.01^{\prime \prime} \mathrm{N}$ & $50^{\circ} 26^{\prime} 13.77^{\prime \prime} \mathrm{N}$ & $43^{\circ} 19^{\prime} 21.50^{\prime \prime} \mathrm{N}$ & $50^{\circ} 30^{\prime} 9.26^{\prime \prime} \mathrm{N}$ \\
\hline & & $2^{\circ} 25^{\prime} 56.15^{\prime \prime} \mathrm{E}$ & $2^{\circ} 21^{\prime} 34.36$ '' $\mathrm{E}$ & $2^{\circ} 53^{\prime} 0.24^{\prime \prime} \mathrm{E}$ & $5^{\circ} 211^{\prime} 37.05^{\prime \prime} \mathrm{E}$ & $3^{\circ} 41 ' 56.53$ ' $\mathrm{E}$ \\
\hline Sample depth & $\mathrm{m}$ & 2 & 8 & 7 & 10 & 6 \\
\hline BC - black carbon & $\%$ & 0.00 & 0.06 & 0.66 & 0.22 & 0.35 \\
\hline TOC & $\%$ & 3.20 & 2.85 & 13.9 & 4.93 & 10.6 \\
\hline$\sum 14 \mathrm{PAH}^{2}$ & $\mu \mathrm{g} \mathrm{kg}^{-1}$ & 2550 & 7710 & 45700 & 37100 & 3360 \\
\hline$\sum 7 \mathrm{PCB}^{3}$ & $\mu \mathrm{g} \mathrm{kg}^{-1}$ & 75 & 541 & 539 & 3530 & 318 \\
\hline Oil $\left(\mathrm{C}_{10}-\mathrm{C}_{40}\right)$ & $\mathrm{mg} \mathrm{kg}^{-1}$ & 4590 & 3170 & 9580 & 5340 & 6310 \\
\hline Oil /TOC & $\%$ & 14.3 & 11.1 & 6.9 & 10.8 & 6.0 \\
\hline Texture & & Sandy-silty & Silty-sandy & Clayey silt & Silty-sandy & Clayey silt \\
\hline
\end{tabular}

${ }^{1}$ highway sedimentation tank

${ }^{2}$ naphthalene, acenaphthene, acenaphthylene, fluorene, phenanthrene, anthracene, fluoranthene, pyrene, chrysene, benz[a]anthracene, benzo $[a]$ pyrene, indeno[ $[1,2,3-c, d]$ pyrene, dibenz $[a, h]$ anthracene, benzo $[g, h, i]$ perylene

${ }^{3}$ CB28, CB52, CB101, CB118, CB138, CB153, CB180 
Table 2. Relationships between $\mathrm{K}_{\mathrm{BC}}, \mathrm{K}_{\mathrm{oil}}$ and $\mathrm{K}_{\mathrm{ow}}$ for PAHs and PCBs.

\begin{tabular}{|c|c|c|c|}
\hline $\begin{array}{c}\text { Studied } \\
\text { contaminant }\end{array}$ & Equation & Relationships $\mathrm{f}\left(\log \mathrm{K}_{\mathrm{ow}}\right)$ & References \\
\hline PAHs & 7 & $\log K_{B C}=1,6 \log K_{o w}-1,4$ & (Schwarzenbach et al., 2003) \\
\hline PAHs & 8 & $\log K_{B C}=0,6997 * \log K_{o w} *+2,8219$ & (Koelmans et al., 2006) \\
\hline PAHs & 9 & $\log K_{\text {Oil }}=0,1287 * \log K_{\text {ow }} *+6.2943$ & (Koelmans et al., 2009) \\
\hline PAHs & 10 & $\log \mathrm{K}_{\mathrm{Oil}}=0,9052 * \log \mathrm{K}_{\mathrm{ow}} *+0.9079$ & (Jonker et al., 2003) \\
\hline PCBs & 11 & $\log K_{B C}=0,912 * \log K_{o w} * *+1,370$ & (Werner et al., 2010) \\
\hline PCBs & 12 & $\log K_{B C}=1,016 * \log K_{o w} * *+0,2469$ & (Koelmans et al., 2006) \\
\hline PCBs & 13 & $\log K_{B C}=0,980 * \log K_{o w} * *+0.491$ & (Moermond et al., 2005) \\
\hline PCBs & 14 & $\log K_{\text {Oil }}=0,9948 * \log K_{o w} * *+0,9787$ & (Jonker and Barendregt, 2006) \\
\hline
\end{tabular}

*PAH $\log \mathrm{K}_{\mathrm{ow}}$ from Mackay et al. (1992); **PCB $\log K_{\mathrm{ow}}$ from Hawker and Connell. (1988) 


\title{
Polyethylene passive samplers to determine sediment-porewater distribution coefficients of persistent organic pollutants in five heavily contaminated dredged sediment
}

\author{
Benoit Charrasse, Céline Tixier, Pierre Hennebert and Pierre Doumenq
}

\section{LIST OF FIGURES}

Fig.1. Exchange rate coefficients $\left(\mathrm{k}_{\mathrm{e}}\right)$ as a function of $\log \mathrm{K}_{\mathrm{ow}}$ for passive sampling experiments with LDPE strips exposed to Lens sediment with PAHs ( $\square)$, PAH-PRCs $(\square)$, PCBs $(\Delta)$ and PCB-PRCs $(\triangle)$

Fig.2. First-order dissipation rate constant (logk $\mathrm{e}_{\mathrm{e}}$ ) of PAH PRCs into LDPE membrane samplers for $\square$ Evry, $O$ Dunkerque, $\triangle$ Lens, $\times$ Marseille and $\diamond N B$ sediments

Fig.3. The solid line is $1: 1$ Modeled $\log K_{d} / \log K_{\text {Toc }}$ against experimental $\log _{\mathrm{d}} / \log \mathrm{K}_{\text {Toc }}$ for the five studied sediments for PAHs (on the left, considering with Raoult's Law model) and for PCBs (on the right, considering triple sorption model). The solid line is 1:1. The internal dashed lines represent the domain suitable for a factor of 10 ( 1 log difference). The external dashed lines correspond to the domain suitable for a factor of $30(\approx 1.5 \log$ difference) 




Fig.1. Exchange rate coefficients $\left(\mathrm{k}_{\mathrm{e}}\right)$ as a function of $\log \mathrm{K}_{\mathrm{ow}}$ for passive sampling experiments with LDPE strips exposed to Lens sediment with PAHs (ם), PAH-PRCs ( $\square)$, PCBs $(\mathbf{\Delta})$ and PCB-PRCs $(\triangle)$ 


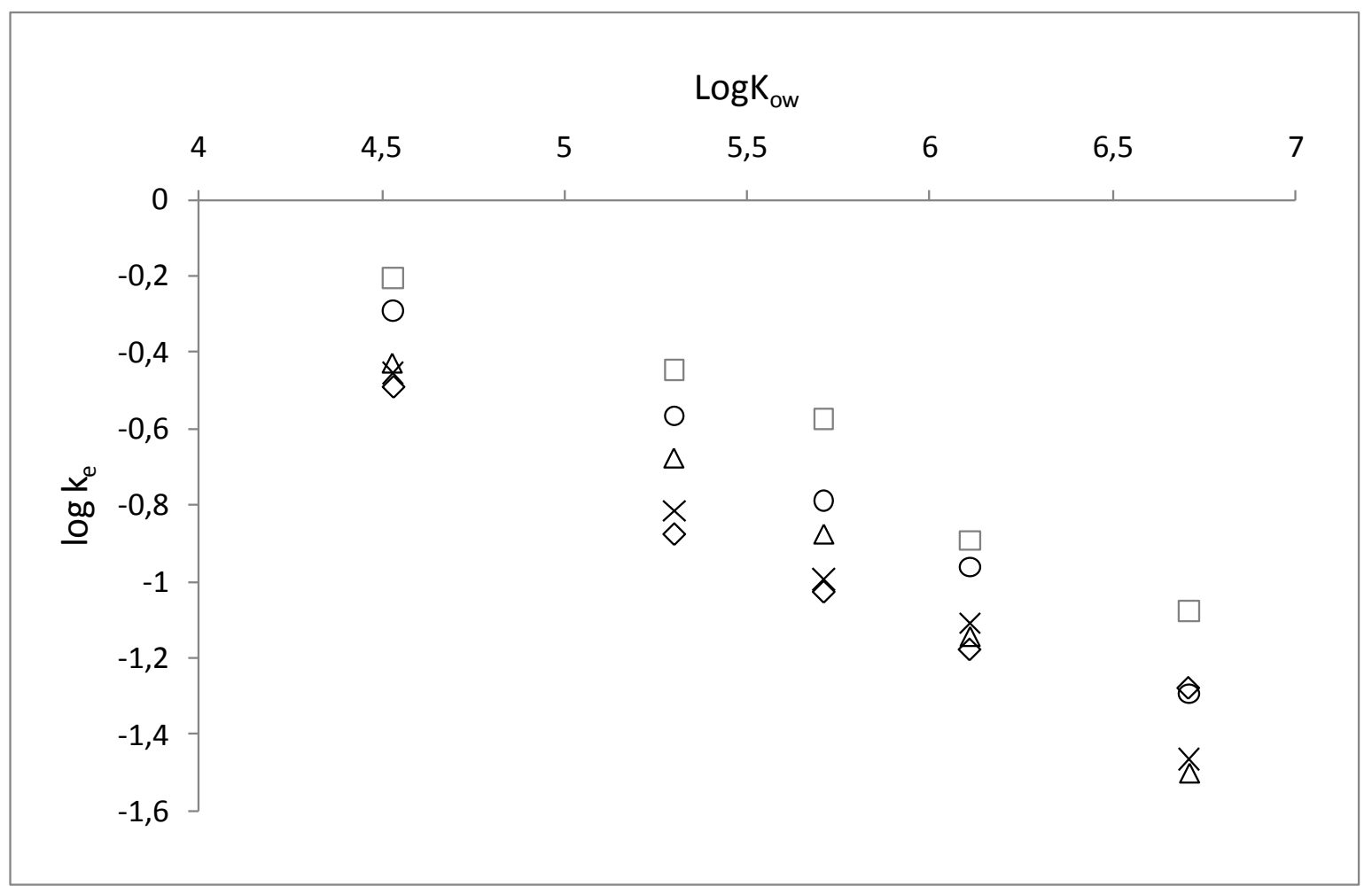

Fig.2. First-order dissipation rate constant $\left(\log \mathrm{k}_{\mathrm{e}}\right)$ of PAH PRCs into LDPE membrane samplers for $\square$ Evry, $\bigcirc$ Dunkerque, $\triangle$ Lens, $\times$ Marseille and $\diamond$ NB sediments 




Fig.3. The solid line is 1:1Modeled Log $K_{d} / \log K_{T O C}$ against experimental Log $K_{d} / \log K_{T O C}$ for the five studied sediments for PAHs (on the left, considering with Raoult's Law model) and for PCBs (on the right, considering triple sorption model). The solid line is 1:1. The internal dashed lines represent the domain suitable for a factor of 10 (1 log difference). The external dashed lines correspond to the domain suitable for a factor of $30(\approx 1.5 \log$ difference). 